\title{
Best of Times, Worst of Times: Occupational Mental Health Research in India
}

\author{
Chinchu $\mathrm{C}^{1}$ \\ ${ }^{I}$ (Department of Psychology, Periyar University Salem, India)
}

\begin{abstract}
The global burden of mental health problems is on the rise, with particular sections being more vulnerable. Industrial population is facing the risk of mental health issues much more than the general population. Realizing the potential risk of such a trend, efforts are afoot worldwide to promote positive mental health, and to provide remedial measures. The problem is more complex in societies with inadequate awareness levels and huge treatment gaps. Recently, India has seen a number of interventions in the area of community mental health care but a contextual focus on mental wellbeing promotion in workplaces is deficient. One reason is the lack of concrete definitions and evidence-based research in occupational mental health. Various researchers have pointed out the need for context-specific research in mental health. Also, there has been a definitive shift in the approach towards mental health, whereby the illness-centric model is being gradually replaced by a focus on wellness and positivity. This paper examines the current state of mental health research with a focus on Indian workplaces and attempts to put forward a definition for occupational mental health which is rooted in the positivity approach as advocated by various forums including the World Health Organization.
\end{abstract}

Keywords: India, Mental Health, Occupational Mental Health, Positive Mental Health,

\section{INTRODUCTION}

It is not an overstatement to say that we live in an age of paradoxes. Indices of positive human functioning are showing trends of all-round progress which necessarily indicates that we are on the right way to a better future for ourselves. On individual levels, our life expectancies have increased; health care facilities are improving, better means of comfort are being introduced and so on. On the other hand, issues like stress, burnout, interpersonal crises, lifestyle diseases, etc. are on the rise. Viewed from a sociological perspective, there seems to be structural issues with the way humans are organizing themselves as a global society.However, one important concern for the researchers in the area of social sciences has to do with the bad impact left by the technological progress on human lives. Stress and related symptoms threaten the wellbeing of an ever-increasing number of people, with an imminent chance of an existential crisis looming over. There has been a consensus in opinions that the burden of mental health problems is consistently on the rise in every part of the world [1]. It is alarming to note that depression is slated to become the second contributor for the disease burden worldwide [2]. While no perfect solutions are on offer for any of these issues, a growing realization regarding the need for strengthening the human response to stressors has been one ray of hope.

Movements like Global mental health have given an impetus to the efforts to consider mental health as an entity distinct from - even though not entirely unrelated to - mental illness, and to combat the stigma attached to mental illnesses [3].There is a renewed focus on the twin aspects of mental illness prevention and mental health promotion as a unified strategy. The need for approaching the issue of mental health from contextual perspectives [4] is emphasized more than ever before. This paper reviews the current trends in Mental Health research and argues for a renewed focus on Occupational Mental Health, from the perspective of Positive Psychology.

\section{THE MOST VULNERABLE}

Problems inherent to the working population have been a topic of discussion for quite a long time. The issue of alienation has been predicted to affect the wellbeing and satisfaction of an employee [5]. When mental health and mental illness are approached from the perspective of contexts, it becomes clear that certain sections of the society are more vulnerable than others to suffer from mental illnesses. Globally, the industrial workforce is facing the risk of mental disorders of varying kinds when compared to the general population. While poverty has been undoubtedly linked to anxiety and related problems, having a job and the environment at the workplace have also been inexplicably linked to some mental health issues. Mental disorders contribute to at least $7 \%$ of the cost of work-related diseases according to some estimates [6]. This is one problem with a cascading effect on the overall functioning of any industry, and in turn, the larger society. Another pertinent fact is that costs 
related to mental problems are preventable to a great extent with the help of focused and carefully designed interventions.

\section{THE INDIAN SCENARIO}

The Indian economy has been shifting slowly from an agrarian base to more diversification, especially after the significant changes introduced following the Liberalization, Privatization, Globalization (LPG) wave worldwide. The linkage of the Indian economy with the open market capitalist economy was strengthened which led to some extensive transformations in the life of typical Indians, that too in all walks of life. Introduction of new job avenues and the rise in the number of opportunities as well as the competitive nature of the new job market - all had lasting impacts on the wellbeing of the Indian population. The demographic variety which is unique to the country has added another dimension to the study of the cultural and behavioural impacts of these sudden changes. The employees in the Indian IT/BPO sector have been experiencing a number of mental health issues, especially stress- related problems [7]. This is one job sector which has seen a spurt of growth in the recent decades. Prevalence of mental disorders in the general population is around 5\% which by itself is almost equivalent to the entire population of the United States of America or that of Italy. The prevalence rate of mental disorders among Indian industrial population is even higher, estimated to be between fourteen to thirty-seven percent [8].The nature of mental illnesses found among the Indian working population is similar to what is observed elsewhere, with stress and anxiety being most common [9]. The problem of stressrelated issues faced by the industrial population has assumed such proportions that the mainstream society has begun discussing it as an important public health issue [10]. It has to be conceded that the issue of mental health problems at workplace is not just a topic of academic interest anymore. There is a need to consider the issue as a community mental health problem. Policy-level decisions and evidence-based interventions designed with the support of all stakeholders is the need of the hour.

\section{THE FOCUS ON POSITIVITY AND WELLNESS}

In the mental health academia, there has been a paradigm shift of sorts. The focus of mental health research has accommodated - if not fully integrated - into its framework the concept of positive psychology. Although the beginnings of this change can be traced back to the works of Abraham Maslow [11], who coined the term 'Positive Psychology' or the seminal work of Marie Jahoda [12], who wrote on a positive direction for mental health, the palpable shift in perceptions happened only in the first decade of the current century, when the field of positive psychology has been taken seriously by researchers, practitioners and the community, albeit with critique and corrections [13]. Proponents of positive psychology have tried to provide a theoretical and empirical base to the field so that avenues of research can be strengthened with the help of new findings [14]. Close on the heels of the positive psychology movement is the similarly novel development of the wellness perspective in mental health and wellbeing. This stream of thought brought to light the importance of factors like subjective wellbeing, psychological wellbeing and happiness in ensuring positive mental health of people [15] ; [16]. Constructs from the domain of positive psychology began to be tailored for use in the promotion of wellbeing in various contexts. The concept of flourishing as a tool for mental health promotion is one of the notable contributions from this new wave of positive insights [17]. The models of practice borne out of wellness research [18] have been applied in a wide variety of areas across cultural, geographical and disciplinary boundaries, with several research outcomes, including doctoral research theses being produced in a short span of time [19]. The advent of a wellness perspective as a welcome departure from an illness-centric medical model of mental health is construed as a move in the right direction.

Need for contextual focus

Another important understanding that has occurred in the mental health research field is the need for contextual focus in approach. It has been accepted that positive mental health or wellbeing in different contexts are different in nature, with its determinants and correlates being diverse [4]. This has been a welcome departure from the traditional focus on context-free or generic approach to mental health. Evidently, a context-specific focus will help the research become more robust and effective. Research in mental health with concerted focus on various settings like schools [20], military [21], geriatrics [22], etc. have been taken up frequently in the recent times.

The situation in India is not really optimistic when compared with the worldwide trend. There exists a huge treatment gap and non-availability of appropriate psychological services or trained professionals in the country [23]; [24]; [25]. Various factors including the vast demographic diversity, linguistic divisions, cultural barriers, illiteracy, age-old stigma attached to mental illnesses and lack of awareness have confounded the problem of demand-availability gap in psychological services. There are certain areas which provide a silver lining though. Efforts have been taken sparingly to provide mental health services at various levels through community mental health initiatives, largely inspired by the global mental health movement and the World Health Organization Mental Health Gap Action Plan. [1]; [26]; [27]; [28]. Such endeavours provide testimony 
that interventions, borne out of strong evidence and empirical understandings can actually work even in the difficult situations as represented by the Indian experience.

\section{OCCUPATIONAL MENTAL HEALTH: AN OVERVIEW}

The emergence of context-specific subfields in the practice of psychology is thus a felt need of the society. India is grappling with a grave problem of treatment gap in mental health, which is another factor that supports the setting up of community-level and context-specific approaches to mental health promotion. The need for concrete definitions of original concepts like occupational mental health is substantiated by a few factors.

- The worldwide movement in mental health research with a clear focus on positivity, wellness and happiness [14]; [29]; [30]; [31]

- The growing realization of the significance of context-specificity in Well-being research, especially with reference to workplaces [4]; [32]

- The ambiguity and lack of concreteness in current definitions of occupational mental health [33]; [6]; [34]

Defining mental health comprehensively is difficult. However, a definition is necessary for operational reasons, especially when research and interventions are concerned. One of the most inclusive and popular definitions is given by World Health Organization [35] as a state of well-being in which the individual realizes his or her own abilities, can cope with the normal stresses of life, can work productively and fruitfully, and is able to make a contribution to his or her community. This definition stands out particularly for its focus on positive functioning and the 'more than a lack of mental illness' spirit. It is a culmination of a long stream of thought about how to define mental health, with traceable roots in health research [36].

Drawing on this definition of mental health by WHO, an attempt is made here to define occupational mental health with a positive outlook and taking into account the contextual features of the modern workplace. One issue that confronts us here is the fact that the concept of a workplace itself is not amenable to a monolithic definition. Workplaces of our age are diverse enough so as to make it near impossible to arrive at a single definition that fits them all. To tackle this problem, the scope of the term can be delimited to include the modern workplaces which originated in the last century, the ones that are organized, assume some form of hierarchy and bureaucratic organization and follow some form of defined time and compensation structures. One constant feature that is seen generally in the modern workplaces is the occurrence of stress [37] and the problems that accompany workplace stress [38]. The association between workplaces and stress is not a topic of academic interest anymore. Even newspapers or popular media in India are discussing the same on a regular basis, along with academic research inputs [7]; [8]; [9]; [39].

Thus, taking into consideration the significant need for addressing mental health in workplace contexts, and the wellness-based definition of mental health offered by WHO, a definition of occupational mental health is proposed as 'a state of wellbeing in which a person realizes her or his worth and potential, can work productively, can cope with the normal stresses at work, and is able to contribute to her or his organization and to the society'.

\section{CONCLUSION}

Recent advancements in technology have brought about a number of innovations in the field of healthcare. Smartphone applications have introduced new avenues for better inclusion in all areas, including prevention and health promotion [40]. Mental health is one of the areas that has benefitted a lot from such innovations [41]. This opportunity can be integrated with the findings and evidence-base of contextual areas of mental health research. Prevention and wellness promotion are the latest trends that can go hand-in-hand with the advent of occupational mental health research. Tools developed for the assessment of occupational mental health can be useful for advancing evidence-based research in the area. The concepts of occupational mental health can be integrated to the current revolution in mental healthcare being ushered in by smartphone-based mental health apps [42] which hold a lot of promise for the general public. This becomes even more significant in places like India which suffer from a huge treatment gap [43]. Systematic studies and Randomized Controlled Trials conducted with the help of such technological advancements coupled with the backbone provided by context-specific theoretical formulations are sure to help a lot in ensuring better wellbeing in the Indian workplace by supplying much-needed empirical data and insights for intervention design. While the ubiquitous nature of technology in the modern workplace is seen as a bane by many, it can definitely be used as a tool in our fight against workplace problems. Research in occupational mental health is a definitive tool which can be of immense potential in such an endeavour. 


\section{ACKNOWLEDGEMENT}

This work is part of the $\mathrm{Ph} \mathrm{D}$ research of the author, guided by the Dr. S. Kadhiravan, Professor and Head, Department of Psychology, Periyar University, Salem and is funded by University Grants Commission under its Junior Research Fellowship scheme.

\section{REFERENCES}

[1] Herrman, H., Saxena, S., Moodie, R., World Health Organization, Victorian Health Promotion Foundation, \& University of Melbourne (Eds.).. Promoting mental health: concepts, emerging evidence, practice. (Geneva: World Health Organization. 2005)

[2] Murray, C., \& Lopez, A.. The global burden of disease. (Boston: Harvard School of Public Health, WHO and The World Bank. 1996)

[3] Jacob, K. S., \& Patel, V.. Classification of mental disorders: a global mental health perspective. The Lancet, 383(9926), (2014), 1433-1435.

[4] Briner, R. B.. Relationships between work environments, psychological environments and psychological well-being. Occupational Medicine (Oxford, England), 50(5), (2000), 299-303.

[5] Marx, Karl. Comments on James Mill, ÉlémentsD’économiePolitique. In C. Dutt (Trans.), Collected Works. (London: Lawrence \& Wishart 1987).

[6] Harnois, G., \& Gabriel, P. Mental health and work: impact, issues and good practices. (Geneva: World Health Organization 2000).

[7] Padma, V., Anand, N. N., Gurukul, S. M. G. S., Javid, S. M. A. S. M., Prasad, A., \&Arun, S.. Health problems and stress in Information Technology and Business Process Outsourcing employees. Journal of Pharmacy \&Bioallied Sciences, 7(Suppl 1), (2015) S9-S13. http://doi.org/10.4103/0975-7406.155764

[8] Dutta, S., Kar, N., Thirthalli, J., \& Nair, S. Prevalence and risk factors of psychiatric disorders in an industrial population in India. Indian Journal of Psychiatry, 49(2), (2007), 103-108. http://doi.org/10.4103/0019-5545.33256

[9] Kar, N. Mental ill health in workers: observations from a few Indian populations. Occupational and Environmental Medicine, 60(3), (2003), 225-225. http://doi.org/10.1136/oem.60.3.225-a

[10] Venugopal, V. A big challenge for IT employees. The Hindu. (2010, September 13), Chennai. Retrieved from http://www.thehindu.com/sci-tech/health/a-big-challenge-for-it-employees/article627693.ece

[11] Maslow, A. H. Motivation and Personality. (New York: Harper \& Brothers. 1954)

[12] Jahoda, M. Current concepts of positive mental health. (New York: Basic Books. 1958)

[13] Froh, J. J. The history of positive psychology: Truth be told. NYS Psychologist, 16(3), (2004) 18-20.

[14] Seligman, M. E., \& Csikszentmihalyi, M. Positive psychology. An introduction. The American Psychologist, 55(1), (2000), 5-14.

[15] Diener, E., Suh, E., Lucas, R., \& Smith, H. Subjective well-being: three decades of progress. Psychological Bulletin, 125(2), (1999), 276-302.

[16] Ryan, R. M., \& Deci, E. L. On happiness and human potentials: a review of research on hedonic and eudaimonic well-being. Annual Review of Psychology, 52, (2001), 141-166. http://doi.org/10.1146/annurev.psych.52.1.141

[17] Keyes, C. L. M. Promoting and protecting mental health as flourishing: a complementary strategy for improving national mental health. The American Psychologist, 62(2), (2007), 95-108. http://doi.org/10.1037/0003-066X.62.2.95

[18] Myers, J. E., Sweeney, T. J., \& Witmer, J. M. The wheel of wellness counseling for wellness: A holistic model for treatment planning. Journal of Counseling and Development: JCD, 78(3), (2000) 251.

[19] Myers, J. E., \& Sweeney, T. J. Wellness in Counseling: An Overview (ACAPCD-09). (Alexandria, VA: American Counseling Association. 2007) Retrieved from http://www.counseling.org/docs/defaultsource/library-archives/professional-counselor-digest/acapcd-09.pdf?sfvrsn=4

[20] Evans, S. W. Editorial. School Mental Health, 1(1), (2009), 1-2 http://doi.org/10.1007/s12310-009-9004$\mathrm{y}$

[21] Kessler, R. C., Heeringa, S. G., Stein, M. B., Colpe, L. J., Fullerton, C. S., Hwang, I., ... Ursano, R. J. Thirty-day prevalence of dsm-iv mental disorders among nondeployed soldiers in the us army: Results from the army study to assess risk and resilience in service members (army starrs). JAMA Psychiatry, 71(5), (2014) 504-513. http://doi.org/10.1001/jamapsychiatry.2014.28

[22] World Health Organization. WHO | Mental health and older adults. (Geneva: World Health Organization. 2016). Retrieved from http://www.who.int/mediacentre/factsheets/fs381/en/

[23] Patel, V. Where there is no psychiatrist: a mental health care manual. (London: Gaskell. 2002).

[24] Prakash, O., \& Kukreti, P. State of Geriatric Mental Health in India. Current Translational Geriatrics and Experimental Gerontology Reports, 2(1), (2012), 1-6. http://doi.org/10.1007/s13670-012-0034-1 
[25] Reddy, V. B., Gupta, A., Lohiya, A., \& Kharya, P. Mental Health Issues and Challenges in India: A Review. International Journal of Scientific and Research Publications, 3(2), (2013) 1-3.

[26] Faqurudheen, H., Mathew, S., \& Kumar, T. M., Exploring Family Resilience in a Community Mental Health Setup in South India. Procedia Economics and Finance, 18, (2014) 391-399. http://doi.org/10.1016/S2212-5671(14)00955-1

[27] Patel, V., Weobong, B., Nadkarni, A., Weiss, H. A., Anand, A., Naik, S., ... Kirkwood, B. The effectiveness and cost-effectiveness of lay counsellor-delivered psychological treatments for harmful and dependent drinking and moderate to severe depression in primary care in India: PREMIUM study protocol for randomized controlled trials. Trials, 15, (2014). 101. http://doi.org/10.1186/1745-6215-15101

[28] Shidhaye, R., Shrivastava, S., Murhar, V., Samudre, S., Ahuja, S., Ramaswamy, R., \& Patel, V. Development and piloting of a plan for integrating mental health in primary care in Sehore district, Madhya Pradesh, India. The British Journal of Psychiatry: The Journal of Mental Science, 208 Suppl 56, (2016). s13-20. http://doi.org/10.1192/bjp.bp.114.153700

[29] Keyes, C. L. M., \& Lopez, S. J. Toward a science of mental health: Positive directions in diagnosis and interventions. In C. R. Snyder \& S. J. Lopez (Eds.), Handbook of positive psychology (pp. 45-59). (London: Oxford University Press 2002)

[30] Ganga, N. S., \&Kutty, V. R. Measuring Positive Mental Health: Development of the Achutha Menon Centre Positive Mental Health Scale. Asia-Pacific Journal of Public Health, 27(2), (2015), NP1893NP1906. http://doi.org/10.1177/1010539512444119

[31] Trompetter, H. R., de Kleine, E., \& Bohlmeijer, E. T.. Why Does Positive Mental Health Buffer Against Psychopathology? An Exploratory Study on Self-Compassion as a Resilience Mechanism and Adaptive Emotion Regulation Strategy. Cognitive Therapy and Research. (2016) http://doi.org/10.1007/s10608016-9774-0

[32] Dextras-Gauthier, J., Marchand, A., \& Haines III, V. Organizational culture, work organization conditions, and mental health: A proposed integration. International Journal of Stress Management, 19(2), (2012), 81-104. http://doi.org/10.1037/a0028164

[33] Fingret, A. Occupational mental health: a brief history. OCCUPATIONAL MEDICINE-OXFORD-, 5O(5), (2000), 289-293.

[34] Roberts, R. K., Swanson, N. G., \& Murphy, L. R. Discrimination and occupational mental health. Journal of Mental Health, 13(2), (2004), 129-142. http://doi.org/10.1080/09638230410001669264

[35] World Health Organization. Promoting mental health: concepts, emerging evidence, practice : summary report. (Geneva: World Health Organization 2004)

[36] Bertolote, J. The roots of the concept of mental health. World Psychiatry, 7(2), (2008), 113-116.

[37] Kahn, R. L., \& Dunnette, M. D. Stress in organizations. In L. M. Hough (Ed.), Handbook of industrial and organizational psychology (Vol. 3, pp. 571-650). (Palo Alto, CA: Consulting Psychologists Press, 1992)

[38] Nieuwenhuijsen, K., Bruinvels, D., \& Frings-Dresen, M. Psychosocial work environment and stressrelated disorders, a systematic review. Occupational Medicine, 60(4), (2010), 277-286. http://doi.org/10.1093/occmed/kqq081

[39] Kesavachandran, C., Rastogi, S. K., Das, M., \& Khan, A. M. Working conditions and health among employees at information technology - enabled services: a review of current evidence. Indian Journal of Medical Sciences, 60(7), (2006), 300-307.

[40] Bedno, S. A., \& Vicsik, D. M.. Public Health in the Smartphone Era. Medscape. (2012). Retrieved from http://www.medscape.com/viewarticle/776278

[41] Goodwin, J., Cummins, J., Behan, L., \& O’Brien, S. M. Development of a mental health smartphone app: perspectives of mental health service users. Journal of Mental Health, (2016), 1-7. http://doi.org/10.3109/09638237.2015.1124392

[42] Bakker, D., Kazantzis, N., Rickwood, D., \& Rickard, N. Mental Health Smartphone Apps: Review and Evidence-Based Recommendations for Future Developments. JMIR Mental Health, 3(1), (2016), e7. http://doi.org/10.2196/mental.4984

[43] Yellowlees, P., \& Chan, S. Mobile mental health care - an opportunity for India. The Indian Journal of Medical Research, 142(4), (2015), 359-361. http://doi.org/10.4103/0971-5916.169185

[44] Title Adapted from Dickens, C. A tale of two cities (1st ed.). (England: Chapman and Hall 1859) 